\title{
Energy and exergy analysis in an asphalt plant's rotary dryer
}

\author{
D. Peinado $^{\mathrm{a}, \mathrm{b}, *}$, M. de Vega ${ }^{\mathrm{b}}, \mathrm{N}_{\text {. García-Hernando }}^{\mathrm{b}}$, C. Marugán-Cruz $^{\mathrm{b}}$ \\ a Intrame SA, Research \& Development Department, Spain \\ ${ }^{\mathrm{b}}$ Energy Systems Engineering Group (ISE), Department of Thermal and Fluid Engineering, Carlos III University of Madrid, Spain
}

\begin{abstract}
A B S T R A C T
In this paper, energy and exergy analyses of a rotary dryer employed in a Hot Mix Asphalt (HMA) plant for heating and drying of the aggregates in the mixture is presented. In the analysis, the exergy method in addition to the more conventional energy analysis, is employed to identify and evaluate the ther modynamic losses. The results show that, at design conditions, the plant performs with energy and exergy efficiencies of 0.89 and 0.18 , respectively. The energy losses are mainly due to the flue gases. The exergy distribution indicates that the combustion and the heat transfer at different temperatures in the burner yield the highest exergy destruction in the process. A parametric study is conducted for the plant under various operational production parameters, including different humidities of the aggregates and filler content in aggregates, working temperatures and ambient conditions, in order to determine the parameters that affect the plant performance. It is shown that the solids humidity has a great impact on energy requirements. A better and sustainable use of the heat source employed in the dryer is proposed to avoid the high irreversibilities found. Furthermore, operating corrections in the mix or in the exhaust gas temperature are proposed to optimize the performance of the plant.
\end{abstract}

\section{Introduction}

At present, paved surfaces can comprise up to $45 \%$ of land cover in urban regions of the United States [1]. Worldwide, the present global urbanization rate and the overall increase in the population are generating a high demand for new road networks. This level of activity suggests significant sustainability implications. In a recent review of 14 roadway construction papers, Muench [2] revealed some data on the energy and environmental impacts of roadway construction, in particular, that the energy expended during roadway construction is roughly equivalent to that used by traffic operating on the facility for 1 or 2 years, and that the total $\mathrm{CO}_{2}$ emissions during roadway construction vary typically between 200 and $600 \mathrm{Mg} / \mathrm{lane}$ mile.

In most countries, the pavement of these motor roads, airfields and other trafficked areas is made of hot mix asphalt (HMA), a mixture prepared in asphalt mixing plants. In these HMA production plants, once the asphalt cement (bitumen) has been produced and shipped, it is stored in large containers and heated to ensure fluidity and proper coating of the aggregates. During the HMA production, aggregates are conveyed from stockpiles to dryers where they are heated to a temperature between 150 and $200{ }^{\circ} \mathrm{C}$.

\footnotetext{
* Corresponding author. Intrame SA, Research \& Development Department, Spain. E-mail address: diego.peinado@intrame.com (D. Peinado).
}

The aggregates are then mixed with the hot asphalt cement, producing the final HMA mixture. The Hot Mix Asphalt Concrete Industry has produced around 1600 million metric tons of Hot Mix Asphalt (HMA) during 2007 all around the world [3]. A con servative figure of how much energy is needed to manufacture one metric ton of HMA is around $85 \mathrm{kWh}$ [4]. Therefore, the total quantity of energy consumed in this sector can be estimated in $136 \cdot 10^{6} \mathrm{MWh} / \mathrm{year}$. On the other hand, the average world crude oil production during 2007 was 84,523 millions of barrels per day in average [5]. This means that the whole industry of HMA consumed $0.28 \%$ of the world's crude oil production. The minimization of energy requirements for manufacturing HMA and the associated lowering of asphalt plant emissions, have therefore become important issues.

There has been an increasing interest in energy and exergy analysis modeling techniques for energy utilization assesments, in many sectors such as power generation, heating and refrigeration. Nevertheless, the literature in construction processes and materials is more scarce, although in the cement production literature studies have been found where energy and exergy analyses were used. Çamdali et al. [6] carried out energy and exergy analyses of a dry system rotary burner with pre calcinations in a cement plant, including thermal and chemical processes: results showed that while the calculated energy efficiency is $97 \%$, the calculated exergy efficiency is only $64.4 \%$, providing an indication of the location of the degradation of energy. Rasul et al. [7] identified the thermal 
energy conservation opportunities on the basis of energy and exergy balances of the kiln and cooler systems of an existing cement industry. Utlu et al. [8] using actual operational data in a cement plant, performed the energy and exergy analysis of the raw mill and raw materials preparation unit in a cement plant for evaluating its performance. Sogut et al. [9] investigated the trass mill process of a similar cement industry for the first time in terms of energy and exergy balances. In both cases [8,9], the chemical exergies of the substances were neglected. Also Sogut et al. [10] investigated the potential of recovering the waste energy in the rotary kiln of a cement industry: the waste energy potential was determined with an exergy analysis. All these studies were realized at a single given operational condition.

In the case of the asphalt mixing plants, literature concerning energy savings and environmental impact is even more scarce. New technologies are being developed by the asphalt industries, seeking a lower energy requirement to blend asphalt mixes, which, in return, will result in less fuel consumption and reduced emission of greenhouse gases, such as Warm mix asphalt (WMA), that enables the mixing and compaction of asphalt mixes at lower temperatures [11]. Recently, Jullien et al. [12] studied the influence of operating parameters on airborne emissions at the asphalt plant stack for a given set of production conditions. Results highlight the correlation in emission flows with combustion intensity and energy consump tion, and combustion efficiency. In fact, the energy consumption in HMA plants is mainly due (more than $97 \%$ ) to the heating and drying of the aggregates in combustion devices. Both processes are there fore key factors in energy savings and sustainability, but to the authors knowledge, a detailed thermodynamic study of the dryer system itself is missing in the literature. As far as the authors know, only an investigation of the use of energy in asphalt mixing plants was done by Ang et al. [13]. This work covered an energetic inven tory analysis in the production process involving the mixing of granite aggregates and bitumen to give asphalt mixtures, with special concern on the aggregate moisture content, which results to be a critical determinant of process energy requirements, but availability or irreversibilities in the plant were not considered.

Based on reviewing the studies conducted on HMA plants and particularly in the combustion and drying processes taking place in the burner, it may be concluded that no studies using the energy and exergy analyses have appeared in the open literature to the best of the authors' knowledge. This was the motivation behind performing the present study. In this regard, the objectives of this contribution are as follows: (i) identify the main energy losses and irreversibilities for the first time in the dryer system of an asphalt plant, where humidity and combustion factors have to be taken into account, as well as the filler content in aggregates; (ii) provide guidelines for operation corrections in view of energy savings and improved availability of the drying and heating process by means of a sensitivity analysis. This has not been found in the literature, not even in similar processes; (iii) Encourage the use of a cogeneration system (gas turbine) in order to avoid the huge exergy losses found in the asphalt industry.

This paper is organized as follows: first, the mass, energy and exergy balance equations are presented, where the two main phenomena, combustion and drying, are analysed and the energy and exergy efficiencies are defined. Chemical reactions, aggregate moisture content and ambient air humidity are considered in the balance equations. Results, calculated for the nominal operating condition, demonstrate that while the energy efficiency is high, the process is highly irreversible. Finally, the effect on the energy and exergy fluxes of the main operational parameters of the system, varying in the ranges that usually are found in actual working plants, are investigated for the plant performance analysis and improvement.

\section{Hot Mix Asphalt production}

Conventional HMA is a composite material, whose major components are: the aggregates (sand and coarse aggregates), the filler and the bitumen. Sometimes additives are incorporated to improve the performance of the product, such as adhesion agents, modifiers or fibres [4].

The reinforcement of this composite is the graded aggregates which constitute approximately $90 \%$ in mass of the mixture. The matrix consists of a mastic composed by the bitumen, the filler and, sometimes additives; where the bitumen is the $5 \%$ of the mixture, and the filler the remaining 5\%. Although, these proportions can vary depending on the recipe of the mixture.

The HMA is manufactured in asphalt plants which are an assembly of equipment that performs the following operations: store and feed the HMA constitutive materials, process them if necessary, dose and mix the materials, and store the final product. These plants can be divided in continuous and discontinuous plants. We will focus on discontinuous plants.

Our work will be concerned with two of the three main constitutive materials: the aggregates (comprising the fine and coarse aggregates) and the dust filler.

The other main component, the bituminous binder, is not taken into account in the energy and exergy balances since it does not participate in the heating and drying of the aggregates, as it is only used as a percentage of the final mixture. The binder is stored in tanks, which are maintained at enough temperature to reduce its viscosity.

The aggregates, separated by sizes, are stored in bins where the initial volumetric dosing is made. Later, they are dried and heated up to an appropriate temperature to mix them efficiently. This process is made at a direct fired rotary dryer.

The mass of solids, $m_{s}$, entering the dryer can be divided in two: the mass of the aggregates, $m_{a g}$, and the mass of the aggregate dust (filler), $m_{a g, d}$. When the aggregates are dried and heated in the rotatory dryer, part of the aggregate dust is elutriated with the flue gases, $m_{e, d}$, and the rest is retained with the solids, $m_{r, d}$. Since the HMA recipe specifies the content of dust filler in the final mixture, $m_{m, d}$, which is larger than the amount of dust filler retained in the solids, an extra amount of filler, $m_{i, d}$, has to be injected in the mixing tower. This injected filler will be either commercial filler dust or part of the elutriated dust recovered in the bag filter.

It is useful to define the mass fraction of the filler at the different steps of the process: the mass fraction of filler at the entrance of the dryer, $f_{a g}$, retained in the aggregates, $f_{r}$, or elutriated with the flue gases, $f_{e}$, are calculated as the ratio of mass of the dust to the solids mass, $m_{s}$, whereas the mass fraction of the filler in the final mixture, $f_{m}$, is defined as the ratio of the dust in the HMA to the mass of aggregates and filler in the mixture $\left(\begin{array}{ll}m_{m} & m_{a g}+m_{r, d}+m_{i, d}\end{array}\right)$.

It is evident that when the dust recovered in the filter is not used as the injected filler, part of the energy used to heat and dry the aggregates is lost. Furthermore, even when it is used, since at the bag filter the temperature decreases, the global efficiency is reduced by the elutriation of the filler dust at the dryer.

Therefore the expression for the mass fraction of the injected filler is:

$f_{i} \frac{f_{m}\left(1 f_{a g}+f_{r}\right) f_{r}}{1 f_{m}}$

In our model all the injected filler comes from the bag filter, which constitutes the so called reclaimed filler. It is possible to include in our model the commercial filler, by setting $f_{i}$ to zero.

In the asphalt plants, the conditioning and drying of the aggre gates are done by means of a rotary dryer. Rotary dryers are commonly used in different industries to dry granular solids. They 
are made of a long cylindrical shell with its axis with a slight downward slope and their rotation induces the axial motion of the solids. In the direct fired dryers, the hot gas stream is produced inside the dryer in a special zone by a combustion of a gaseous, liquid or solid fuel. The drying section usually has internal parts (flights) that elevate the granular materials and make them fall through the hot gas stream to increase the specific contact surface $[14,15,16,17]$.

\section{Model of the drying process}

In the direct fired dryer two main processes take place: the fuel combustion with fresh air at ambient conditions, and the drying of the aggregates as they receive the heat of the combustion. The following assumptions will be made: the aggregates are at ambient temperature, the liquid water that constitutes the solids humidity is also at ambient temperature, the fresh air is humid air with the relative humidity corresponding to the ambient conditions, the pressure drop in the dryer is neglected, and the process pres sure is taken equal to the dead state pressure.

In this work the fuel considered is liquid heavy fuel oil. Never theless, the extension to other kind of fuels (e.g. natural gas, micronized coal, etc.) is straightforward.

\subsection{Combustion reaction equations}

We will first model the combustion reaction in order to obtain the relationships among the mass flow rates of fuel, air and water vapor, considering at first instance, that the air combustion is dry air.

The reaction between heavy fuel oils and atmospheric air with a stoichiometric ratio, $\lambda$, can be written as:

$$
\begin{aligned}
& \mathrm{C}_{n_{\mathrm{C}}} \mathrm{H}_{n_{\mathrm{H}}} \mathrm{S}_{n_{\mathrm{S}}} \mathrm{O}_{n_{\mathrm{O}}} N_{n_{N}}\left(\mathrm{H}_{2} \mathrm{O}\right)_{n_{\mathrm{H}_{2} \mathrm{O}}} \\
& +\lambda\left(n_{C}+\frac{n_{H}}{4}+n_{S}+n_{N} \quad \frac{n_{O}}{2}\right)\left(O_{2}+3.76 N_{2}\right) \\
& \rightarrow n_{C} \mathrm{CO}_{2}+\left(n_{\mathrm{H}_{2} \mathrm{O}}+\frac{n_{\mathrm{H}}}{2}\right) \mathrm{H}_{2} \mathrm{O}+n_{\mathrm{S}} \mathrm{SO}_{2}+n_{\mathrm{N}} \mathrm{NO}_{2} \\
& +\left(\begin{array}{ll}
\lambda & 1
\end{array}\right)\left(n_{C}+\frac{n_{H}}{4}+n_{S}+n_{N} \quad \frac{n_{O}}{2}\right) O_{2} \\
& +\lambda \cdot 3.76\left(n_{C}+\frac{n_{H}}{4}+n_{S}+n_{N} \quad \frac{n_{O}}{2}\right) N_{2}
\end{aligned}
$$

The stoichiometric (i.e. $\lambda$ 1) mass air-fuel ratio $\varphi$ is obtained as:

$\varphi \frac{\left(n_{C}+\frac{n_{H}}{4}+n_{S}+n_{N} \frac{n_{O}}{2}\right) \cdot\left(M_{O_{2}}+3.76 \cdot M_{N_{2}}\right)}{n_{C} M_{C}+n_{H} M_{H}+n_{S} M_{S}+n_{O} M_{O}+n_{N} M_{N}+n_{H_{2} O} M_{H_{2} O}}$

We will be modeling, on one hand, the water contained in the flue gases, and on the other, the dry combustion gases. In particular, the mass of water generated in the combustion per unit mass of fuel, $\mathrm{K}_{\mathrm{H}_{2} \mathrm{O}}$, will be:

$K_{\mathrm{H}_{2} \mathrm{O}} \frac{\left(n_{\mathrm{H}_{2} \mathrm{O}}+\frac{n_{H}}{2}\right) \cdot M_{\mathrm{H}_{2} \mathrm{O}}}{n_{C} M_{C}+n_{H} M_{H}+n_{S} M_{S}+n_{O} M_{O}+n_{N} M_{N}+n_{H_{2} O} M_{H_{2} O}}$

For a given mass of fuel, $m_{F}$, the necessary dry air, $m_{a}$, the water vapor generated, $m_{v c}$, in combustion and the dry combustion, gases mass, $m_{d c g}$, can therefore be calculated as:

$m_{a} \quad \lambda \cdot \varphi \cdot m_{F}$

$m_{v c} \quad K_{H_{2} \mathrm{O}} \cdot m_{F}$

$m_{d c g} \quad\left(1+\lambda \cdot \varphi \quad K_{\mathrm{H}_{2} \mathrm{O}}\right) m_{F}$

\subsection{Mass and energy balance equations}

In Fig. 1 we represent the energy terms associated with the different materials into and out of the dryer, as well as the thermal losses. For convenience, to establish the energy balance, we have distinguished the dry combustion gases, $\dot{m}_{d c g}$, and the water vapor mass flow, $\dot{m}_{v_{\text {out }}}$, at the dryer outlet. The later is divided in the contributions of the air inlet humidity, $\dot{m}_{v_{i n}}$, the drying process, $\dot{m}_{v D}$, and the combustion generated water, $\dot{m}_{v c}$.

Since the specific surface is larger in the smaller particles, the mass and heat transfer mechanisms are more vigorous in the filler. Therefore, the retained liquid water at the outlet is expected to be only in the aggregates, and not in the elutriated filler.

The mass flow of liquid water associated to a wet solid is expressed as $\dot{m}_{w} \quad X \dot{m}_{s}$. The solids humidity at the outlet, $X_{\text {out }}$, is also related to the solid mass, $m_{s}$. The atmospheric water vapor content is $\dot{m}_{v} \quad \omega \dot{m}_{a}$. Using results from Section 3.1, equations (5), (6), and (7), and the definition of the elutriated filler mass fraction, we have:

$$
\begin{aligned}
& \dot{m}_{a} \lambda \varphi \dot{m}_{F} \\
& \dot{m}_{v_{\text {in }}} \quad \dot{m}_{a} \omega_{\text {in }} \quad \lambda \varphi \omega_{\text {in }} \dot{m}_{F} \\
& \dot{m}_{w_{i n}} \quad X_{i n} \dot{m}_{s_{i n}} \\
& \dot{m}_{S_{\text {out }}} \quad\left(1 \quad f_{e}\right) \dot{m}_{s_{\text {in }}} \\
& \dot{m}_{e, d} \quad f_{e} \dot{m}_{s_{i n}} \\
& \dot{m}_{d c g} \quad\left(1+\lambda \varphi \quad K_{H_{2} \mathrm{O}}\right) \dot{m}_{F} \\
& \dot{m}_{v_{\text {out }}} \quad \dot{m}_{F} K_{\mathrm{H}_{2} \mathrm{O}}+\dot{m}_{F} \lambda \varphi \omega_{\text {in }}+\dot{m}_{s_{\text {in }}}\left(X_{\text {in }} \quad X_{\text {out }}\right) \\
& \dot{m}_{w_{\text {out }}} \quad X_{\text {out }} \dot{m}_{s_{\text {in }}}
\end{aligned}
$$

The fuel mass flow, $\dot{m}_{F}$, is to be determined from the energy balance, depending on the solid mass flow of solids to be processed in the plant, $\dot{m}_{s_{i n}}$.

The energy balance in a control volume can be stated as:

$\frac{d E_{c v}}{d t} \quad \sum_{\text {in }}\left(\dot{m}_{i} h_{i}\right) \quad \sum_{\text {out }}\left(\dot{m}_{i} h_{i}\right)+\dot{Q} \quad\left(\dot{W}_{c v}+p \frac{d V_{c v}}{d t}\right)$

at a steady state and without any work interaction ${ }^{1}$ :

$\sum_{\text {out }}\left(\dot{m}_{i} h_{i}\right) \quad \sum_{\text {in }}\left(\dot{m}_{i} h_{i}\right) \quad \dot{Q}$

The computation of the enthalpies is done considering ideal solid, ideal liquid and ideal gas models with constant specific heat. The dry combustion gases composition has been calculated according to equation (2) from the mass fraction composition for a typical fuel. The mean value of the calculated specific heat of the dry combustion gases with this composition is compared with the one computed from the dry air composition. The difference is below $1 \%$, so the same value is used for fresh dry air and dry combustion gases.

To calculate the fuel enthalpy, the enthalpy of reaction $h_{F}^{\text {ch }}$ has to be taken into account. According to Moran [18] this enthalpy is related to the Low Heating Value, $L H V^{T_{r}}$.

$\dot{m}_{F} h_{F}^{c h} \quad \dot{m}_{F} L H V^{T_{r}}$

\footnotetext{
1 The work needed to rotate the drum is around $1 / 200$ the thermal power
} introduced by the burner. 


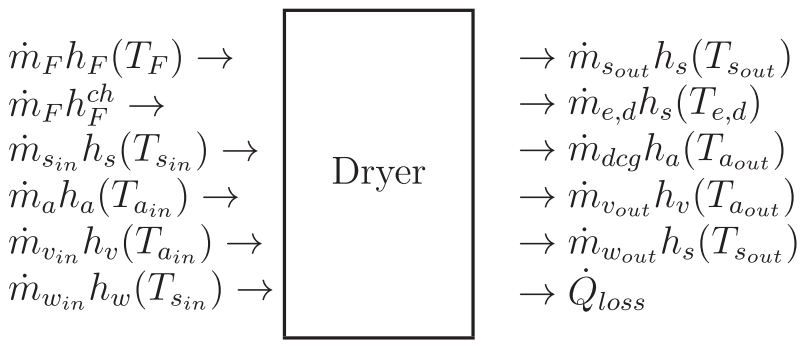

Fig. 1. Energy balance in the dryer.

Using the same temperature reference, $T_{r}$, for all the enthalpies the next expressions follow:

$$
\begin{aligned}
& \dot{m}_{F} h_{F}\left(T_{F}\right) \quad \dot{m}_{F} c_{p F}\left(T_{F} \quad T_{r}\right) \\
& \dot{m}_{s_{i n}} h_{s}\left(T_{s_{\text {in }}}\right) \quad \dot{m}_{s_{\text {in }}} c_{p s}\left(T_{s_{\text {in }}} \quad T_{r}\right) \\
& \dot{m}_{a} h_{a}\left(T_{a_{i n}}\right) \quad \dot{m}_{F} \lambda \varphi c_{p a}\left(T_{a_{i n}} \quad T_{r}\right) \\
& \dot{m}_{v_{i n}} h_{v}\left(T_{a_{i n}}\right) \quad \dot{m}_{F} \lambda \varphi \omega_{i n}\left(h_{f g}^{T_{r}}+c_{p v}\left(T_{a_{i n}} \quad T_{r}\right)\right) \\
& \dot{m}_{w_{\text {in }}} h_{w}\left(T_{s_{\text {in }}}\right) \quad \dot{m}_{s_{i n}} X_{i n} c_{p w}\left(T_{s_{i n}} \quad T_{r}\right) \\
& \dot{m}_{S_{\text {out }}} h_{s}\left(T_{S_{\text {out }}}\right) \quad \dot{m}_{s_{\text {in }}}\left(1 \quad f_{e}\right) c_{p s}\left(T_{S_{\text {out }}} \quad T_{r}\right) \\
& \dot{m}_{e, d} h_{s}\left(T_{e, d}\right) \quad \dot{m}_{s_{i n}} f_{e} c_{p s}\left(T_{e, d} \quad T_{r}\right) \\
& \dot{m}_{d c g} h_{a}\left(T_{a_{\text {out }}}\right) \quad \dot{m}_{F}\left(1+\lambda \varphi \quad K_{H_{2} O}\right) c_{p a}\left(T_{a_{\text {out }}} \quad T_{r}\right) \\
& \dot{m}_{v_{\text {out }}} h_{v}\left(T_{a_{\text {out }}}\right) \quad \dot{m}_{F}\left(\left(K_{H_{2} \mathrm{O}}+\lambda_{\varphi \omega_{\text {in }}}\right) c_{p v}\left(T_{a_{\text {out }}} \quad T_{r}\right)+\lambda \varphi \omega_{\text {in }} h_{f g}^{T_{r}}\right) \\
& +\dot{m}_{s_{\text {in }}}\left(X_{\text {in }} \quad X_{\text {out }}\right)\left(h_{f g}^{T_{r}}+c_{p v}\left(T_{a_{\text {out }}} \quad T_{r}\right)\right)
\end{aligned}
$$

$\dot{m}_{w_{\text {out }}} h_{S}\left(T_{S_{\text {out }}}\right) \quad \dot{m}_{s_{\text {in }}} X_{\text {out }} c_{p w}\left(T_{S_{\text {out }}} \quad T_{r}\right)$

It is important to notice that to calculate the vapor enthalpy, equation (27), the terms corresponding to the water produced in the combustion process, the inlet wet air and the drying process have to be considered.

In the dryer, two main streams have to be considered: one associated with the aggregates to be dried, which includes the dry solid flow, the elutriated filler flow, and the solids humidity (liquid and gas phase), hereinafter named process stream $(p)$. The other, associated with the combustion, which includes the gases used to heat and dry the aggregates and the fuel in liquid phase, hereinafter named combustion gases stream $(\mathrm{cg})$.

We can separate the contributions of each stream:

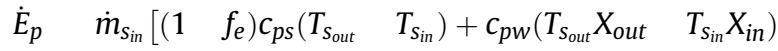

$$
\begin{aligned}
& +\left(\begin{array}{ll}
X_{\text {in }} & X_{\text {out }}
\end{array}\right)\left(h_{f g}^{T_{r}}+c_{p v} T_{a_{\text {out }}}\right)+f_{e} c_{p s}\left(T_{e, d} \quad T_{s_{\text {in }}}\right) \\
& \left.+\left(\begin{array}{ll}
c_{p w} & c_{p v}
\end{array}\right)\left(X_{\text {in }} \quad X_{\text {out }}\right) T_{r}\right] \\
& \dot{m}_{s} e_{p} \\
& \dot{E}_{c g} \quad \dot{m}_{F}\left[(1+\lambda \varphi) c_{p a}\left(T_{a_{\text {out }}} \quad T_{a_{\text {in }}}\right)\right. \\
& +K_{\mathrm{H}_{2} \mathrm{O}}\left(c_{p v} \quad c_{p a}\right)\left(T_{a_{\text {out }}} \quad T_{r}\right)+\lambda \varphi \omega_{\text {in }} c_{p v}\left(T_{a_{\text {out }}} \quad T_{a_{\text {in }}}\right)
\end{aligned}
$$

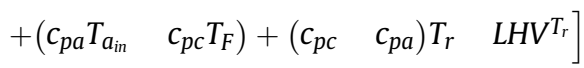

$$
\begin{aligned}
& \dot{m}_{F} e_{f g} \quad \dot{E}_{\text {burner }} \quad \dot{E}_{f g} \quad \dot{E}_{\text {burner }}
\end{aligned}
$$

Where $\dot{E}_{f g}$ is the flue gases thermal power, and the change in chemical enthalpy from reactants to products is: $\dot{E}_{\text {burner }} \quad \dot{m}_{F} L H V^{T_{r}}$.

The terms $\left(\begin{array}{lll}c_{p a} T_{a_{\text {in }}} & \left.c_{p F} T_{F}\right) \text { and } K_{\mathrm{H}_{2} \mathrm{O}} T_{a_{\text {out }}}\left(c_{p_{v}}\right. & c_{p_{a}}\end{array}\right)$ are small corrections due to change of composition. They have opposite signs so their global effect is small in comparison with the other terms.

Applying equation (17) and taking into account that the only

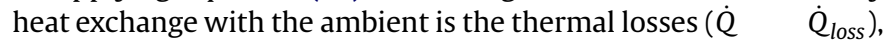
then we can obtain:

$\dot{E}_{p}+\dot{E}_{f g}+\dot{Q}_{\text {loss }} \quad \dot{E}_{\text {burner }}$

$\dot{Q}_{\text {loss }}$ is calculated as a fraction of the heat introduced:

$\dot{Q}_{\text {loss }} k \cdot\left(\dot{E}_{p}+\dot{E}_{f g}\right)$

We are interested in calculating the fuel and energy requirements for a given quantity of processed solids. Taking into account that the bitumen mass fraction $\left(f_{b}\right)$ is about $5 \%$, the aggregate solid mass flow can be calculated as:

$m_{s_{i n}} \quad \frac{\left(1 \quad f_{b}\right)}{1 f_{e}+f_{i}} m_{m}$

Using equations (29)-(32), the fuel to solid mass ratio is found to be:

$\frac{\dot{m}_{F}}{\dot{m}_{s_{i n}}} \quad \frac{(1+k) e_{p}}{L H V^{T_{r}} \quad(1+k) e_{f g}}$

With this last expression and equation (14), the humidity ratio at the dryer exit can also be calculated:

$\omega_{\text {out }} \frac{\frac{L H V^{T_{r}}(1+k) e_{f g}}{(1+k) e_{p}}\left(X_{\text {in }} \quad X_{\text {out }}\right)+\lambda \varphi \omega_{\text {in }}+K_{\mathrm{H}_{2} \mathrm{O}}}{1+\lambda \varphi} K_{\mathrm{H}_{2} \mathrm{O}}$

\subsection{Energetic efficiency}

In order to define task efficiencies, we have to define which part of the energy is actually used for the process purpose. The used thermal power is the one employed in heating and drying the aggregates that are effectively used in the final HMA mixture. There are two main sources of waisted thermal power related to the filler in aggregates. One is the consequence of the initial composition of the aggregates, in which the filler is often in excess with respect to the definition of the mix recipe. This filler enters the dryer, it is heated but afterwards rejected from the process, and therefore its energy content is lost. The other source is consequence of the fact that the elutriated filler mass flux cannot be accurately controlled, and therefore a fraction of the reclaimed filler must be reinjected with a lower temperature. We then write the used and waist thermal powers as:

$$
\begin{aligned}
& \dot{E}_{\text {used }} \quad \dot{m}_{s}\left[\begin{array}{lll}
(1 & f_{e}
\end{array}\right) c_{p s}\left(T_{s_{\text {out }}} \quad T_{s_{\text {in }}}\right)+f_{i} c_{p s}\left(\begin{array}{ll}
T_{f i} & T_{s_{\text {in }}}
\end{array}\right) \\
& +c_{p w}\left(X_{\text {out }} T_{S_{\text {out }}} \quad X_{\text {in }} T_{s_{\text {in }}}\right)+\left(\begin{array}{ll}
X_{\text {in }} & X_{\text {out }}
\end{array}\right)\left(h_{f g}^{T_{r}}+c_{p v} T_{a_{\text {out }}}\right) \\
& \left.+\left(\begin{array}{ll}
c_{p w} & c_{p v}
\end{array}\right)\left(X_{\text {in }} \quad X_{o u t}\right) T_{r}\right] \\
& \dot{m}_{s} e_{\text {used }} \\
& \dot{E}_{\text {waist }} \quad \dot{m}_{s}\left[\left(\begin{array}{lll}
f_{e} & f_{i}
\end{array}\right) c_{p s}\left(T_{e, d} \quad T_{s_{i n}}\right)+f_{i} c_{p s}\left(\begin{array}{ll}
T_{e, d} & T_{f i}
\end{array}\right)\right] \quad \dot{m}_{s} e_{w}
\end{aligned}
$$

Finally, the efficiency can be defined as:

$\eta_{t} \frac{\dot{E}_{\text {used }}}{\dot{E}_{\text {burner }}} \quad \frac{L H V^{T_{r}}(1+k) e_{f g}}{(1+k) e_{p}} \frac{q_{\text {used }}}{L H V^{T_{r}}}$ 


\subsection{Exergy balance equations}

The maximum amount of work which can be produced by a stream of matter or energy of different kinds when reaching the equilibrium with a reference environment is known as exergy. Exergy is not conserved, except for ideal or reversible processes. Rather, exergy is consumed or destroyed due to irreversibilities in any real process, where the exergy consumption is proportional to the entropy generation in the process itself [19].

The exergy balance in a control volume can be defined as:

$$
\begin{aligned}
& \frac{d \Psi_{c v}}{d t} \quad \sum_{\text {in }}\left(\dot{m}_{i} \psi_{f_{i}}\right) \quad \sum_{\text {out }}\left(\dot{m}_{i} \psi_{f_{i}}\right)+\sum_{j}\left(\begin{array}{ll}
1 & \left.\frac{T_{0}}{T_{j}}\right) \dot{Q}_{j}
\end{array}\right. \\
& \left(\dot{W}_{c v}+p \frac{d V_{c v}}{d t}\right) \quad \dot{I}
\end{aligned}
$$

The time exergy variation of the control volume is due to the flow exergy difference between the outlet and inlet streams, the exergy variation produced by heat and mechanical work interactions, and the term that accounts for the exergy destruction, $\dot{I}$.

In the steady state with fixed boundaries, without any work interaction, and only heat losses as heat transfer terms, equation (39) leads to:

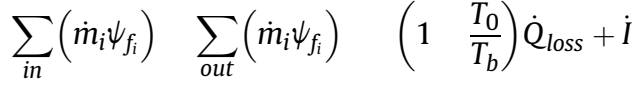

$$
\begin{aligned}
& \text { Or : } \\
& \dot{\Psi}_{\text {in }} \quad \dot{\Psi}_{\text {out }} \quad \dot{\Psi}_{\text {loss }}+\dot{I}
\end{aligned}
$$

Each of the specific exergies will be calculated taking into account the different phases and compositions present in the stream flows [20,21].

The calculation of the exergies is done considering perfect and ideal solid, liquid and gas models. The humid air, the combustion gases and the water vapor from drying are modelled as an ideal mixture of ideal gases.

The mole fractions of air (air and combustion gases), and water vapour are:

$$
\begin{array}{lllll}
x_{v}^{0} & \frac{\varphi^{0} p_{g}\left(T_{0}\right)}{p_{0}} & x_{a}^{0} & 1 & x_{v}^{0} \\
x_{v} & \frac{1.6078 \omega}{1+1.6078 \omega} & x_{a} & 1 & x_{v}
\end{array}
$$

In combustion processes, there is a reacting mixture of substances. A similar analysis than the one presented in Section 3.1 can be done for the fuel exergy calculation. Nevertheless, the industrial liquid fuels are a complex mixture of many hydrocarbons and, usually, there is no thermochemical information for all of them. So a common approach is to use the semi empirical correlation equations that relate the chemical fuel exergy to the $L H V^{T_{r}}$. The chemical exergy expression for liquid fuels is given by Rivero et al. [22]:

$$
\begin{aligned}
& \psi_{c}^{c h} \quad L H V^{T_{r}} \cdot\left[1.0401+0.1728 \cdot \frac{Z_{\mathrm{H}_{2}}}{Z_{C}}+0.0432 \cdot \frac{Z_{\mathrm{O}_{2}}}{Z_{C}}\right. \\
& \left.+0.2169 \frac{Z_{S}}{Z_{C}}\left(\begin{array}{ll}
1 & 2.0628 \\
Z_{C}
\end{array}\right)+0.0428 \frac{Z_{\mathrm{H}_{2}}}{Z_{C}}\right] \\
& L H V^{T_{r}} \cdot \beta
\end{aligned}
$$

With these expressions, and taking into account that $p \quad p_{0}$, the exergy terms can be calculated as:

$\dot{m}_{F} \psi_{F}\left(T_{F}\right) \quad \dot{m}_{F} c_{p F} T_{0}\left[\frac{T_{F}}{T_{0}} \quad 1 \quad \ln \frac{T_{F}}{T_{0}}\right]$

$\dot{m}_{F} \psi_{F}^{c h} \quad \dot{m}_{F} L H V^{T_{r}} \cdot \beta$

$$
\begin{aligned}
& \dot{m}_{s_{i n}} \psi_{s}\left(T_{s_{i n}}\right) \quad \dot{m}_{s_{i n}} c_{p s} T_{0}\left[\begin{array}{lll}
\frac{T_{s_{i n}}}{T_{0}} & 1 & \ln \frac{T_{s_{i n}}}{T_{0}}
\end{array}\right] \\
& \dot{m}_{a} \psi_{a}\left(T_{a_{i n}}\right) \quad \dot{m}_{F} \lambda \varphi T_{0}\left[c_{p a}\left(\frac{T_{a_{\text {in }}}}{T_{0}} \quad 1 \quad \ln \frac{T_{a_{i n}}}{T_{0}}\right)+R_{a} \ln \frac{x_{a_{i n}}}{x_{a}^{0}}\right]
\end{aligned}
$$

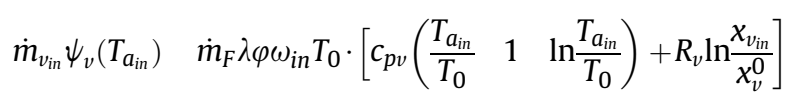

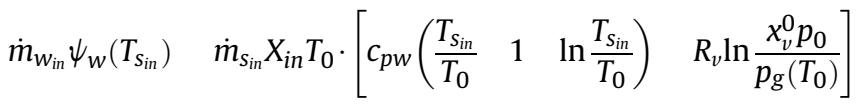

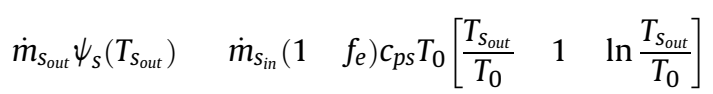

$$
\begin{aligned}
& \dot{m}_{e, d} \psi_{s}\left(T_{e, d}\right) \quad \dot{m}_{s_{\text {in }}} f_{e} c_{p s} T_{0}\left[\begin{array}{lll}
\frac{T_{S_{\text {out }}}}{T_{0}} & 1 & \ln \frac{T_{s_{\text {out }}}}{T_{0}}
\end{array}\right]
\end{aligned}
$$

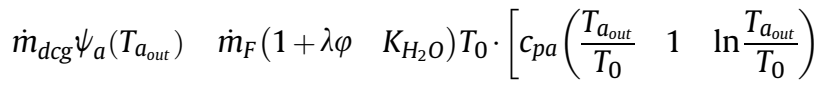

$$
\begin{aligned}
& \left.+R_{a} \ln \frac{x_{a_{\text {out }}}}{x_{a}^{0}}\right] \\
& \dot{m}_{v_{\text {out }}} \psi_{v}\left(T_{a_{\text {out }}}\right) \quad\left[\dot{m}_{F}\left(K_{H_{2} O}+\lambda \varphi \omega_{\text {in }}\right)+\dot{m}_{s_{\text {in }}}\left(X_{\text {in }} \quad X_{\text {out }}\right)\right] . \\
& T_{0}\left[c_{p v}\left(\frac{T_{a_{\text {out }}}}{T_{0}} \quad 1 \quad \ln \frac{T_{a_{\text {out }}}}{T_{0}}\right)+R_{v} \ln \frac{x_{v_{\text {out }}}}{x_{v}^{0}}\right] \\
& \dot{m}_{w_{\text {out }}} h_{s}\left(T_{S_{\text {out }}}\right) \quad \dot{m}_{s_{\text {in }}} X_{\text {out }} T_{0} .
\end{aligned}
$$

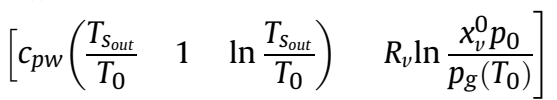

From equation (40) the exergy destruction, $\dot{I}$, can be calculated as:

$\dot{I} \dot{\Psi}_{\text {in }}\left(\dot{\Psi}_{\text {out }}+\dot{\Psi}_{\text {loss }}\right)$

\subsection{Exergetic efficiency}

Different exergetic efficiencies can be defined. The first one is a global efficiency written as:

$\epsilon_{g} \frac{\sum_{\text {out }}\left(\dot{m}_{i} \psi_{f_{i}}\right)}{\sum_{\text {in }}\left(\dot{m}_{i} \psi_{f_{i}}\right)} \quad \frac{\dot{\Psi}_{\text {out }}}{\dot{\Psi}_{\text {in }}} 1 \frac{\dot{I}}{\dot{\Psi}_{1}}$

As in the case of the energy, in order to evaluate task efficiencies, we define the used exergy, waisted exergy and flue gases exergies. We define differences between the exergies of the input and output streams and consider the used and waisted exergy flows as:

$$
\begin{aligned}
& \dot{\Psi}_{\text {used }} \quad \dot{m}_{s}\left(\left(\begin{array}{ll}
1 & f_{e}
\end{array}\right) \psi_{s_{\text {out }}}+f_{i} \psi_{s_{i}}+\left(X_{\text {in }} \quad X_{\text {out }}\right) \psi_{v_{\text {out }}}+X_{\text {out }} \psi_{w_{\text {out }}}\right.
\end{aligned}
$$

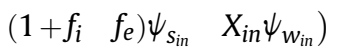

$$
\begin{aligned}
& \dot{\Psi}_{\text {waist }} \quad \dot{m}_{S}\left(f_{e} \psi_{s_{\text {out }}} \quad f_{i} \psi_{s_{i}}\left(f_{e} \quad f_{i}\right) \psi_{s_{\text {in }}}\right) \\
& \dot{\Psi}_{f g} \quad \dot{m}_{F}\left(1+\lambda \varphi \quad K_{H_{2} O}\right) \psi_{a_{\text {out }}}+\left(K_{\mathrm{H}_{2} \mathrm{O}}+\lambda \varphi \omega_{\text {in }}\right) \psi_{v_{\text {out }}} \\
& \left(\lambda \varphi \psi_{a_{\text {in }}}+\lambda \varphi \omega_{\text {in }} \psi_{v_{\text {in }}}\right)
\end{aligned}
$$

The corresponding task exergy efficiency will then be:

$\epsilon_{t} \frac{\dot{\Psi}_{u s e d}}{\dot{m}_{F} L H V^{T_{r}} \cdot \beta}$ 
Table 1

Reference values and range variation of the operational parameters.

\begin{tabular}{lcllccl}
\hline Variable & Reference & Range & Variable & Reference & Range \\
\hline$T_{a m b}\left({ }^{\circ} \mathrm{C}\right)$ & 10 & 050 & $f_{r}(\%)$ & 1 & & 60130 \\
$T_{m_{\text {out }}}\left({ }^{\circ} \mathrm{C}\right)$ & 170 & 150200 & $T_{e, d}\left({ }^{\circ} \mathrm{C}\right)$ & $T_{a_{\text {out }}}$ & 60 & \\
$T_{a_{\text {out }}}\left({ }^{\circ} \mathrm{C}\right)$ & 100 & 60130 & $T_{f}\left({ }^{\circ} \mathrm{C}\right)$ & 80 & & \\
$X_{\text {in }}(\%)$ & 3 & 17 & $\lambda$ & 2.25 & 1.254 .00 \\
$X_{\text {out }}(\%)$ & 0.5 & & $T_{b}\left({ }^{\circ} \mathrm{C}\right)$ & 150 & & \\
$f_{\text {ag }}(\%)$ & 8 & 520 & $\phi_{0}(\%)$ & 50 & 10100 \\
\hline
\end{tabular}

\section{Results}

\subsection{Operational parameters and properties definition}

The present analysis will study a reference asphalt plant working with the operational parameters, indicated in Table 1 . The values and ranges of these parameters correspond to the typical values of commissioned plants, excluding extreme conditions.

The operation values that are considered as input parameters to the model represent mean quantities given by plant operators and expertise at commissioning of plants by INTRAME obtained with industrial sensors. Temperature of the aggregates are measured at the exit of the dryer by an optical pyrometer (Ircon) and by a PT1000. At the exit of the dryer, a portable TESTO 350 emission analyzer measures flue gas emissions providing also the values of the exhaust gas temperature. The measured values are also used to correct the fuel to air ratio, $\lambda$. The remaining temperatures are measured with PT1000. The humidity of the wet product is measured in laboratory by difference in weight of a sample, before and after heating in an oven according to UNE EN 1097 5:2000. The fuel consumption is obtained with a coriolis mass flowmeter (OPTIMASS 8000). The residence time of the aggregates is esti mated in 4-5 min. The mean operation values correspond to typical operating times of $15-20$ min.

The fuel used in the model (heavy fuel oil) is found in many of the commissioned plants. Its composition can be taken as: C $85.5 \%$, $\mathrm{H} 11.5 \%, \mathrm{O} 0.2 \%$ and S $2.8 \%$. Using these values, the composition of the dry combustion gases has been calculated and the corre sponding mass fractions are given in Table 2.

The environment is modelled as shown in Table 2, showing the mole fraction for dry air and for a relative humidity of $50 \%$ when the ambient temperature is $10^{\circ} \mathrm{C}$.

According to previous authors [18,19,23], the dead state must be specified completely, since it determines the value of the exergy fluxes. As it is shown by Göğüş et al. [23] and Ozgener and Ozgener [24], to avoid errors, the dead state conditions have been chosen equal to the ambient atmosphere in composition, pressure and temperature, $T_{0}$.

The reference temperature, $T_{r}$, has been taken as $T_{r} \quad 25^{\circ} \mathrm{C}$. This is the reference temperature for $L H V^{T_{r}}$ and $h_{f g}^{T_{r}}$. To estimate the specific heat of the water vapor, the average temperature between

Table 2

Reference atmosphere composition, dry mole fractions and wet mole fractions for relative humidity of $50 \%\left(10^{\circ} \mathrm{C}\right)$, and mass fraction of the dry combustion gases.

\begin{tabular}{|c|c|c|c|c|}
\hline \multicolumn{3}{|c|}{ Reference atmosphere } & \multicolumn{2}{|c|}{ Dry combustion gases } \\
\hline \multirow[t]{2}{*}{ Specie } & \multicolumn{2}{|c|}{ Mole frac. } & \multirow[t]{2}{*}{ Specie } & \multirow[t]{2}{*}{ Mass fraction } \\
\hline & Dry & $\phi \quad 50 \%\left(10^{\circ} \mathrm{C}\right)$ & & \\
\hline $\mathrm{N}_{2}$ & 0.7803 & 0.7755 & $\mathrm{~N}_{2}$ & 0.7553 \\
\hline $\mathrm{O}_{2}$ & 0.2099 & 0.2086 & $\mathrm{O}_{2}$ & 0.1290 \\
\hline $\mathrm{H}_{2} \mathrm{O}$ & 0.0000 & 0.0061 & $\mathrm{H}_{2} \mathrm{O}$ & 0.0000 \\
\hline $\mathrm{CO}_{2}$ & $3.110^{4}$ & $3.0810^{4}$ & $\mathrm{CO}_{2}$ & 0.1008 \\
\hline \multirow[t]{2}{*}{$\mathrm{Ar}$} & 0.0095 & 0.0094 & $\mathrm{Ar}$ & 0.0131 \\
\hline & & & $\mathrm{SO}_{2}$ & 0.0018 \\
\hline
\end{tabular}

Table 3

General results: mass, energy and exergy terms per metric ton of HMA. Inlet/exit gases humidity.

\begin{tabular}{lrlrllll}
\hline Mass & \multicolumn{1}{c}{ kg } & Energy & kWh & Exergy & kWh & Inlet/Exit gases & \\
\hline$m_{F}$ & 5.65 & $E_{\text {burner }}$ & 63.114 & $\Psi_{\text {in }}$ & 68.183 & $\omega_{\text {in }}$ & 0.0038 \\
$m_{d g c}$ & 176.76 & $E_{p}$ & 57.437 & $\Psi_{\text {out }}$ & 12.358 & $\phi_{\text {in }}$ & $50 \%$ \\
$m_{v_{\text {out }}}$ & 31.06 & & & $I$ & 55.518 & $T_{a_{\text {in }}}$ & $10{ }^{\circ} \mathrm{C}$ \\
$\mathrm{m}_{\mathrm{a}}$ & 176.96 & $E_{\text {used }}$ & 56.571 & $\Psi_{\text {used }}$ & 11.347 & $\omega_{\text {out }}$ & 0.1757 \\
& & $E_{\text {waist }}$ & 0.866 & $\Psi_{\text {waist }}$ & 0.506 & $\phi_{\text {out }}$ & $21.7 \%$ \\
& & $E_{f g}$ & 4.745 & $\Psi_{\text {fg }}$ & 0.504 & $T_{a_{\text {out }}}$ & $100{ }^{\circ} \mathrm{C}$ \\
& & $Q_{\text {loss }}$ & 0.933 & $\Psi_{\text {loss }}$ & 0.307 & & \\
& & $\eta_{t}$ & $89.63 \%$ & $\epsilon_{g}$ & $18.12 \%$ & & \\
\hline
\end{tabular}

the reference temperature, $T_{r}$, and the range of the air exit temperature has been taken [25]. The values used for this study are: $c_{p v} \quad 1.750 \frac{\mathrm{kJ}}{\mathrm{kgK}}, c_{p w} \quad 4.180 \frac{\mathrm{kJ}}{\mathrm{kgK}}$ and $h_{f g} \quad 2547 \mathrm{~kJ}$ for the water phase change enthalpy; and for the aggregates, $c_{p s} \quad 0.880 \frac{\mathrm{kJ}}{\mathrm{kgK}}$

\subsection{General results}

In this section, the production of 1 ton of HMA has been used as a reference to calculate the mass, energy and exergy balance (see Table 3).

The energy required by the burner, $E_{\text {burner, }}$ is almost indepen dent of the fuel composition and it is equal to $E_{\text {burner }} \quad 63.1 \mathrm{kWh}$ per metric ton of HMA. It is worth noting that the energy used by the process, $E_{\text {used }}$, is comparable to the energy produced by the burner, giving a very high energy efficiency ( $\sim 90 \%)$.

The values obtained in Table 3 are in excellent agreement with characteristic values of plants running at a steady state regime; although, in the normal operation, the mean values are often higher due to transient terms, since often the production has to be stopped due to incidents in the supply chain, mainly problems in paving operations or non evenly spaced transportation trucks from plant to the place where paving occurs.

The energy carried by the flue gases is the main source for losses (around 7\%). However, the flue gases temperature cannot be reduced to avoid reaching the dew point in the depuration system, specially when fuel with high sulphur content is used.

For final users, the fuel consumption per HMA ton can be used as a first estimate in their drying operating costs. For a typical asphalt plant, with an HMA production of $200 \mathrm{t} / \mathrm{h}$, the $\mathrm{CO}_{2}$ emissions can be calculated from the values of mass fraction of $\mathrm{CO}_{2}$ (Table 2) and from the flue gases mass, $m_{d c g}$ (Table 3): $\dot{m}_{\mathrm{CO}_{2}} \quad 17.82 \frac{\mathrm{kg}}{\mathrm{t}} \cdot 200 \mathrm{t} \frac{\mathrm{h}}{\mathrm{h}} \quad 3564 \frac{\mathrm{kg}}{\mathrm{h}}$.

Table 3 also shows the results of the exergetic analysis. It is evident that the process is not as efficient in terms of exergy as it is in terms of energy. In fact, the value of the exergy destruction, $I$, is considerably high. In the works by Nishida et al. [26] and Som and Datta [27], the exergy destruction in combustion processes is investigated, and the authors conclude that the exergy destruction can vary between 20 and 50\% of the exergy supplied, depending on the equivalence ratio and the air inlet temperature. In order to elucidate how much of the exergy destruction term is due to combustion in our case, a simplified model is used to account for it. We will decompose the process in two separate steps: first, the adiabatic combustion, followed by the supply of heat for the drying process itself. With the stoichiometric ratio of the reference state, $\lambda \quad 2.25$, the adiabatic flame temperature is calculated as $T_{a f} 1217{ }^{\circ} \mathrm{C}$. For this temperature the specific exergy of the gases and the water vapor are calculated. In this first step, only the water vapor generated in combustion is taken into account. The exergy destruction term, $I_{c}$, is the difference between the chemical exergy of the fuel plus the inlet air at ambient temperature, and the exergy of 
the gases and water vapor at $T_{a f}$. The value of the exergy destruction during combustion is $I_{c} \quad 28.46 \mathrm{kWh}$ per ton of product, and the exergetic global efficiency of the adiabatic combustion is $\epsilon_{g c} \quad 57.53 \%$. If a value of $\lambda \quad 1.00$ is used, then we obtain $I_{c} \quad 19.23 \mathrm{kWh}$ and $\epsilon_{g c} \quad 70.23 \%$. These values are in agreement with Som and Datta [27]. The second step is to estimate the exergy lost when the used energy, $E_{\text {used }}$, is transferred from the hot gases to the product. We will estimate the temperatures of both streams as: for the gases, $T_{\text {high }}\left(T_{a f}+T_{a_{\text {out }}}\right) / 2$ and for the solid, $T_{\text {low }}\left(T_{S_{\text {out }}}+T_{S_{\text {in }}}\right) / 2$. Therefore, the lost exergy due to the heat transfer, $I_{h t}$, can be estimated as:

$I_{\text {ht }} \quad E_{\text {used }}\left(1 / T_{\text {low }} \quad 1 / T_{\text {high }}\right) T_{0}$

For the range of parameters used, the lost exergy due to heat transfer is: $I_{h t} \quad 26.71 \mathrm{kWh}$. Hence, the sum of both contributions, $I_{c}$ and $I_{h t}$, is almost equal to the value in Table 3 for the exergy destruction, $I$, for the whole process.

With these considerations, it can be determined that the combustion process in asphalt plants is responsible of more than a half of this exergy destruction. This result confirms the values obtained by previous studies [19,28].

When varying the stoichiometric ratio from 1.25 to 4 , our model shows that the energy and exergy required by the burner ( $E_{\text {burner }}$ and $\Psi_{\text {in }}$ ) grow as $\lambda$ increases, giving as a result a reduction in the energy efficiency of $\sim 8 \%$. The exergy destruction also increases, leading to a decrease in the global exergy efficiency of $2 \%$ and a reduction in the task exergy efficiency of almost 3\%.

One possible solution to avoid this high irreversibility is to use the high exergy of the combustion gases for the production of work. This could be done with a gas turbine for power generation and the exhaust hot gases will then be used to heat and dry the aggregates.
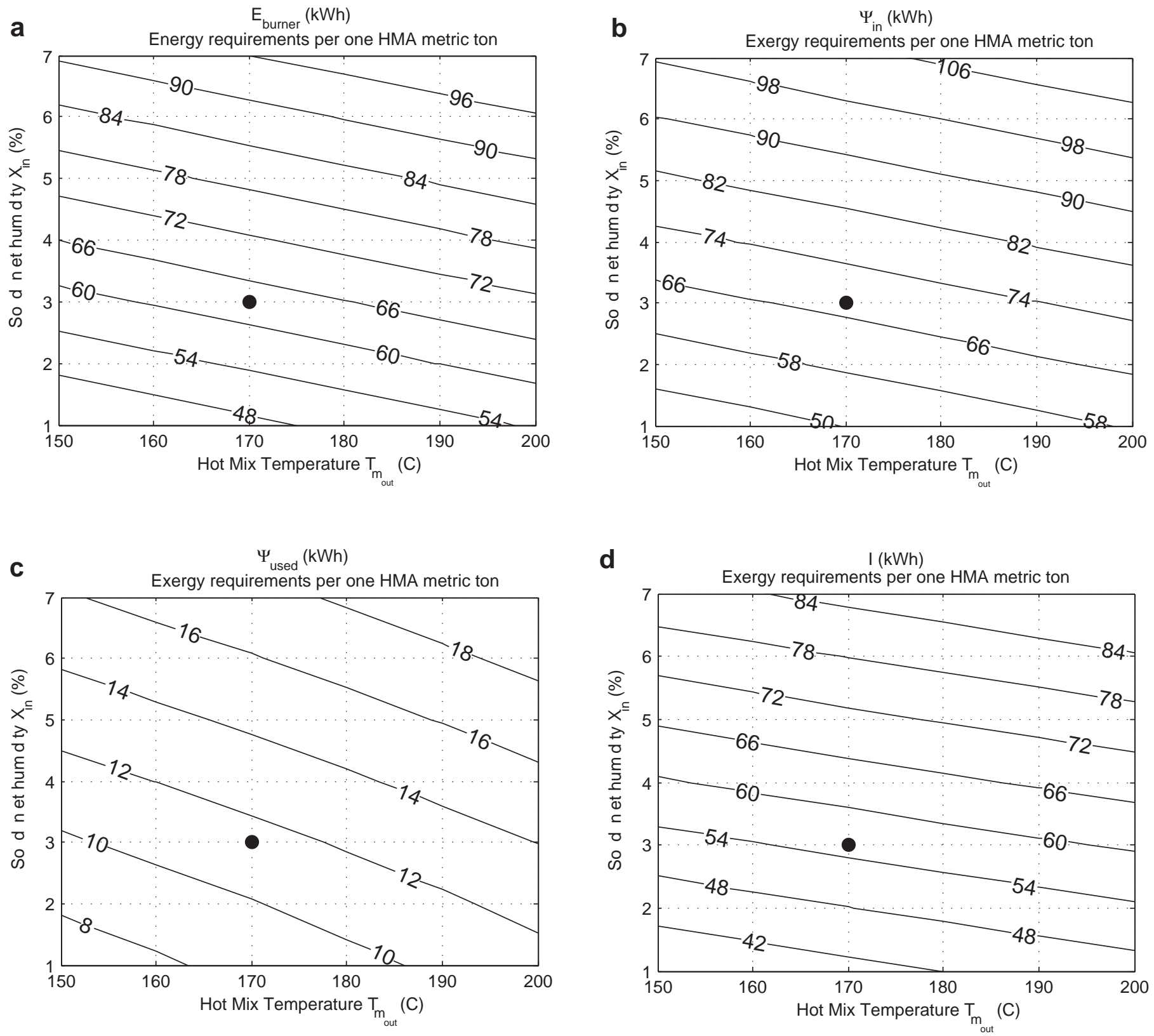

Fig. 2. Energy and exergy analysis: influence of the hot mix temperature and the solids inlet humidity. 


\subsection{Influence of the operating parameters in the plant operation}

We will study in the following the energy, exergy and efficiency values for different operating conditions. The reference state given by the values of Table 1 will be indicated in the figures by a bold circle when appropriate. The ambient temperature and the ambient relative humidity have been varied according to Table 1 . The results of our model show that when increasing the ambient temperature, $E_{\text {burner }}$ decreases as the thermal level of the aggregates is higher and $\eta_{e}$ increases. On the other hand, while $\Psi_{\text {in }}$ decreases with temperature with similar trend of $E_{\text {burner, }}$ the exergetic efficiencies decrease in around $8 \%$. This tendency could be explained as the products are closer to the dead state given by the ambient temperature.

Changes in the ambient relative humidity do not lead to a significant variation in the energy and exergy fluxes. There is a small visible effect in $\epsilon_{g}$, which decreases $3 \%$, but only for important changes in the relative humidity (10\%-100\%).

\subsubsection{Hot mix temperature and solids humidity}

The impact of the hot mix temperature, $T_{m_{\text {out }}}$, and the solids humidity, $X_{i n}$, on the energy and exergy requirements of an HMA plant has been studied (Figs. 2 and 3). The first parameter can be easily controlled in the plant and it should be the minimum temperature that allows an appropriate compaction when paving. However, if the ambient temperature is low and there is a long transportation distance, this temperature has to be risen to compensate thermal losses that occur in the trucks to the paving site. Well planned operations should allow to lower this value as much as possible.

The solids humidity is a very important parameter to control the performance of an asphalt plant. It depends on the extraction procedure at the quarry, on the manner that the aggregates piles are protected from the rain, and on how the front loader operator picks the aggregates from the piles before charging into the feeder bins. Typical ranges encountered in operating asphalt plants in Europe are $1 \%-7 \%$ in mass of the inlet solid.

As seen in Fig. 2a, the solids inlet humidity directly affects the energy required for the drying process: an increase of $4 \%$ in the water content implies a $60 \%$ increase in energy needed by the burner. One way to partially overcome this increase in the demand in the burner may be to decrease the hot mix temperature, while this is possible. The energy demand is about $2.62 \mathrm{kWh}$ higher for an increase of $10{ }^{\circ} \mathrm{C}$ in the mix temperature, and $8.21 \mathrm{kWh}$ higher for each $1 \%$ of solids humidity increase.

When a higher water content is present in the solids, or when the mix temperature is higher, the excess energy needed is employed in the drying or in the improvement of the product; therefore, it has a useful effect. Hence, the energy efficiency is not affected as much.

The effect of the solids inlet humidity augmentation in the exergy fluxes is to increase the inlet exergy and, as occurred with the energy, this supply is mostly invested in drying, and therefore the used exergy also increases (Fig. 2b and c).

Nevertheless, the exergy destruction also increases with the solids humidity as shown in Fig. 2d. The higher needed energy is supplied by a higher fuel mass rate, and therefore, a higher combustion irreversibility occurs.

Fig. 3a and b shows how sensitive the exergetic efficiency is to the temperature of the mix. If the hot mix temperature increases, this excess temperature could be used and, therefore, the exergy efficiency increases (e.g. an augmentation of $20{ }^{\circ} \mathrm{C}$ leads to an increase of $1.2 \%$ in the exergy efficiency). This also can be explained by the fact that a higher hot mix temperature gives a mean temperature of the drying process higher and, therefore, the irre versibility due to the heat transfer from the high combustion gases is smaller (this holds if this effect is high enough, compared to the irreversibility due to the combustion).

The effect of an increase in the solids humidity is more impor tant at higher hot mix temperatures for the exergy efficiencies defined in equations (42) and (43). At mix temperatures above $180{ }^{\circ} \mathrm{C}$, a $5 \%$ increase in inlet humidity of the solids may represent a $1 \%$ decrease in exergy efficiency, while at lower temperatures of the mix, the exergy efficiency remains almost constant.

\subsubsection{Filler fraction in the aggregates and exit gas temperature}

Another important parameter that must be taken into account in the solids characteristics, and that may considerably vary during the operation of an HMA plant, is the filler fraction in the aggre gates, $f_{a g}$. This fraction may vary from $5 \%$ to $20 \%$. Analyzing the deviations from the reference operating condition, we see in Fig. $4 \mathrm{a}$
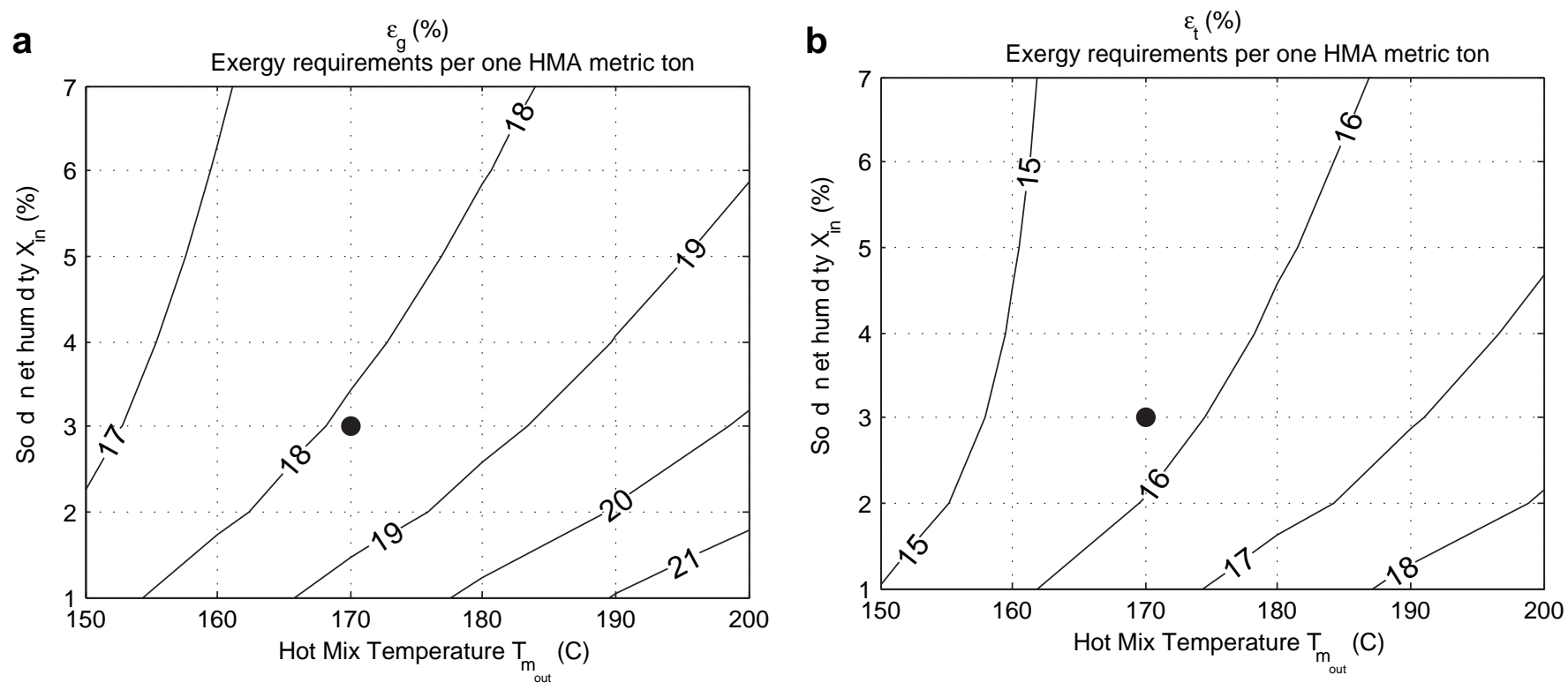

Fig. 3. Exergy analysis: influence of the hot mix temperature and the solids inlet humidity. 

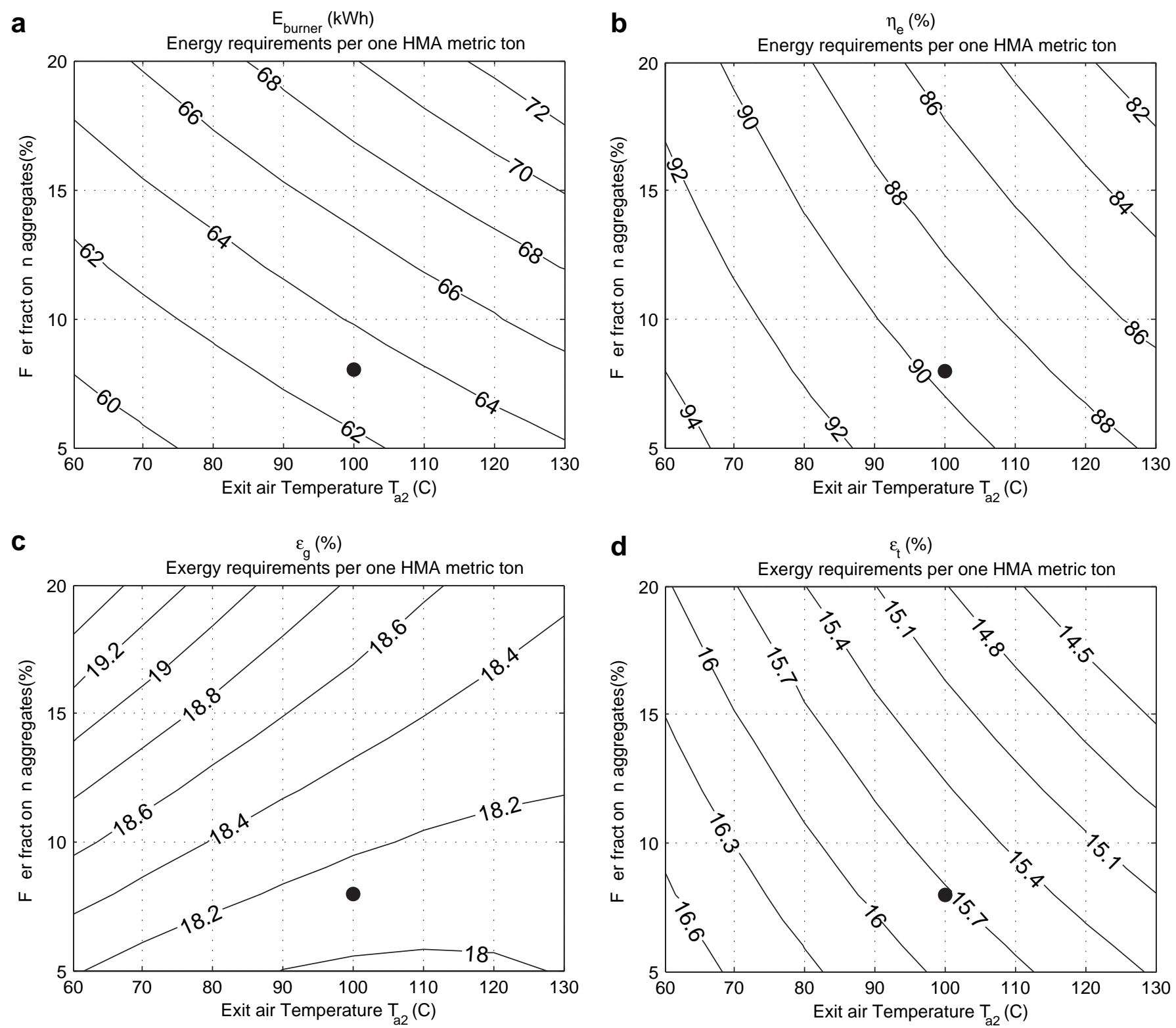

Fig. 4. Energy analysis: dependence of the flue gases temperature with filler fraction in aggregates.

that a $5 \%$ increase in the filler fraction will need a $4.2 \%$ increase of the energy supplied to the burner, but this excess energy is only partially used in the final product, and therefore, the energy effi ciency tends to decrease almost $2 \%$ (Fig. 4b). As introduced in Section 2, the elutriation in the rotary dryer is a mechanism of reducing the global efficiency of the asphalt plant and rising the energy needed per unit mass of final product, giving an approxi mate value of $0.5 \mathrm{kWh}$ when increasing $1 \% f_{m}$.

The energy efficiency, as seen in Fig. 4b, can considerably vary with the exit gas temperature. The gradient of the energy supplied to the burner is maximum when filler content is high and flue gases temperature is also high. In the case of the gradient of the energy efficiency, the decrease in efficiency is also higher in the region of high values of filler content and flue gases temperature. This behavior could be used to balance the differences in filler fraction present in the aggregates. According to Fig. $4 \mathrm{~b}$, if the plant could be operated lowering the temperature of the flue gases in around $10^{\circ} \mathrm{C}$, this efficiency reduction due to the filler increase may be compensated. Unfortunately, this temperature is not always inde pendent of the solids exit temperature, although specific devices on the dryer can be incorporated, as an electronic rotational velocity control.

While varying the temperature of the exit gases for different filler fractions in the aggregates, the exergy input also increases, as occurred with the energy input. Nevertheless, the exergy that is really used, does not increase at the same rate: an augmentation of $20^{\circ} \mathrm{C}$ in the exit gases temperature implies $2.5 \%$ more exergy input, however the exergy used remains almost constant, as the flue gases are not considered as a product. A small variation in exergy, due to filler exit temperature, is obtained.

When the filler fraction in aggregates, $f_{a g}$, increases, the exergy, but also the exergy destruction, increases as well. A 10\% increase in filler fraction needs $8.8 \%$ more exergy in, and the destroyed exergy increases almost in the same way (8.2\%). This explains the trend of the global exergy efficiency (Fig. 4c). It increases slightly with filler fraction and decreases with exit gases temperature. 
A different behavior is obtained for the exergy efficiency defined in equation (43). In Fig. 4d the used exergy efficiency presents a higher decrease with exit gas temperature than the global exergy efficiency, while it decreases with an increase in filler fraction.

\section{Conclusions}

HMA production is a thermal energy consuming industry. When using the heat provided by the combustion of a fuel, a high energy efficiency is obtained for the heating and the drying of the components of the mix recipe. Nevertheless, the present study has shown that the exergetic efficiency is very poor. This low exergetic efficiency is mainly due to, on one hand the high irreversibility due to combustion and, on the other, the high temperature difference between the combustion gases and the product. This suggests that for a more sustainable HMA production, other ways of heating and drying are necessary. To overcome the great exergy destruction the use of a cogeneration plant is proposed to take advantage of the temperature values needed for these plants. Another possibility is to use new production methods as the so called warm mixes or half warm mixes. For these cases, an exergetic analysis should be done in order to elucidate if they can improve the sustainability of the HMA industry.

The parametric study has shown that the hot mix temperature and the solids humidity have great impact on the energy require ments for manufacturing HMA, although the influence on the ener getic efficiency is low. The elutriated filler has also an important effect on the energy requirements. The control of the exit gas temperature through a dryer's rotational velocity controller can improve the plant operation. This could provide an operational guide for a better energy and exergy uses of the energy content in the fuel. This also will contribute to a significant saving in operating costs.

\section{Acknowledgements}

This work has been has been partially funded by the Spanish Government, Project DPI2009 10518 and the Fenix project Research on new concepts for more safe and sustainable roads (CENIT 2007 1014). Also, the authors acknowledge the support provided by Intrame S.A.

\section{Appendix. Nomenclature}

\section{Latin letters}

$K \quad$ mass generated in combustion per unit mass of fuel

$T$ temperature $\left[{ }^{\circ} \mathrm{C}\right]$

$h \quad$ enthalpy $[\mathrm{J} / \mathrm{kg}]$

$c_{p} \quad$ specific heat capacity $[\mathrm{J} / \mathrm{kgK}]$

$f \quad$ mass fraction of filler or other substance

E energy [kWh]

I exergy destruction [kWh]

$Q \quad$ heat $[\mathrm{kWh}]$

W work interaction [kWh]

$X \quad$ solids humidity

mi mass flow rate $[\mathrm{kg} / \mathrm{s}]$

M molecular mass $[\mathrm{kg} / \mathrm{kmol}]$

$n \quad$ number of moles

$y \quad$ mass fraction in an ideal gas mixture

$x \quad$ mole fraction in an ideal gas mixture

\section{Greek letters}

$\lambda \quad$ stoichiometric ratio

$\varphi \quad$ stoichiometric mass air fuel ratio

$\phi \quad$ wet air relative humidity

$\epsilon \quad$ exergetic efficiency $\eta \quad$ energetic efficiency

$\omega$ humidity ratio, or mass basis absolute humidity

$\Psi \quad$ Exergy $[\mathrm{kWh}]$

\section{Superscripts}

ch chemical term for enthalpy and exergy

$T_{r} \quad$ reference temperature for enthalpy $\left[{ }^{\circ} \mathrm{C}\right]$

\section{Subscripts}

a dry air

c combustion

dcg dry combustion gases

$f \quad$ filler

$F \quad$ fuel

$s \quad$ solids

$v \quad$ water vapor

wa wet air

$w \quad$ liquid water

e elutriated

$r \quad$ retained

$i \quad$ injected

ag aggregate

$d \quad$ dust or filler

$p \quad$ process stream

D drying process

$h t \quad$ heat transfer

fg flue gases

\section{References}

[1] P. Whitea, J.S. Goldenb, K.P. Biligiri, K. Kaloushd, Modeling climate change impacts of pavement production and construction, resources, Conservation and Recylcing 54 (2010) 776782.

[2] S.T. Muench, Roadway construction sustainability impact reviews of life-cycle assesments, Transportation Research Record 2151 (2010) 3645.

[3] European Asphalt Pavement Association, Asphalt in Figures, EAPA, http:// www.eapa.org/START/AIF/aif.htm (accessed 18.11.09).

[4] Environmental Guidelines on Best Available Techniques (BAT) for the Production of Asphalt Paving Mixes, European Asphalt Pavement Association, Rue du Commerce 77, 1040 Brussels, Belgium, 2007.

[5] U.S. Energy Information Administration, Official Energy Statistics from the U.S Government, Energy Information Administration, http://www.eia.doe.gov/ ipm/supply.html (accessed 18.11.09).

[6] U. Camdali, A. Erișen, F. Celen, Energy and exergy analyses in a rotary burner with pre-calcinations in cement production, Energy Conversion and Management 45 (2004) 30173031.

[7] M.G. Rasul, W. Widianto, B. Mohanty, Assessment of the thermal performance and energy conservation opportunities of a cement industry in Indonesia, Applied Thermal Engineering 25 (2005) 29502965.

[8] Z. Utlu, Z. Sogut, A. Hepbasli, Z. Oktay, Energy and exergy analyses of a raw mill in cement production, Applied Thermal Engineering 26 (2006) 24792489.

[9] M.Z. Sogut, Z. Oktay, A. Hepbasli, Energetic and exergetic assessment of a trass mill process in a cement plant, Energy Conversion and Management 50 (2009) 23162323.

[10] Z. Sogut, Z. Oktay, H. Karakoç, Mathematical modeling of heat recovery from a rotary kiln, Applied Thermal Engineering 30 (2010) 817825.

[11] M.O. Hamzah, A. Jamshidi, Z. Shahadan, Evaluation of the potencial of Sasobit to reduce required heat energy and $\mathrm{CO}_{2}$, Journal of Cleaner Production doi:10. 1016/j.jclerpro.2010.08.002.

[12] A. Jullien, V. Gaudefroy, A. Ventura, C. de la Roche, R. Paranhos, P. Moneron, Airborne emissions assessment of hot asphalt mixing methods and limitations, Road Material and Pavement Design 1 (2010) 149169.

[13] B.W. Ang, T.F. Fwa, T.T. Ng, Analysis of process energy use of asphalt-mixing plants, Energy 18 (7) (1993) 769777.

[14] J. Kelly, Flight design in rotary dryers, Drying Technology 10 (4) (1992) 979993.

[15] J. Driver, M.T. Harding, T. Howes, G. Palmer, Effect of lifter design on drying performance in rotary dryers, Drying Technology 21 (2) (2003) 369381.

[16] D. Revol, C.L. Briens, J.M. Chabagno, The design of flights in rotary dryers, Powder Technology 121 (2001) 230238.

[17] C.G.J. Baker, The design of flights in cascading rotary dryers, Drying Technology 6 (4) (1988) 631653.

[18] M.J. Moran, Availability analysis, ASME PRESS (1989) ISBN 0-7918-0009-1.

[19] I. Dincer, On energetic, exergetic and environmental aspects of drying systems, International Journal of Energy Research 26 (2002) 717727. 
[20] I. Dincer, A.Z. Sahin, A new model for thermodynamic analysis of a drying process, International Journal of Heat and Mass Transfer 47 (2004) 645652

[21] B.A. Qureshi, S.M. Zubair, Application of exergy analysis to various psychrometric processes, International Journal of Energy Research 27 (2003) 10791094.

[22] R. Rivero, C. Rendon, L. Monroy, The exergy of crude oil mixtures and petroleum fractions: calculation and application, International Journal of Applied Thermodynamics 2 (3) (1999) 115123.

[23] Y.A. . Göğüş, U. Çamdali, M.Ş Kavsaoğlu, Exergy balance of a general system with variation of environmental conditions and some applications, Energy 27 (2002) 625646

[24] L. Ozgener, O. Ozgener, Parametric study of the effect of reference state on energy and exergy efficiencies of a small industrial pasta drying process, International Journal of Exergy 6 (4) (2009) 477490
[25] W. Wagner, J.R. Cooper, A. Dittmann, J. Kijima, H.J. Kretzschmar, A. Kruse, R. Mareǎ, K. Oguchi, H. Sato, I. Stöker, O. Sifner, Y. Takaishi, I. Tanishita, J. Trübenbenbach, T. Willkommen, The IAPWS industrial formulation 1997 for the thermodynamic properties of water and steam, Journal of Engineering for Gas Turbines and Power 122 (2000) 150182.

[26] K. Nishida, T. Takagi, S. Kinoshita, Analysis of entropy generation and exergy loss during combustion, Proceedings of the Combustion Institute 29 (2002) 869874.

[27] S.K. Som, A. Datta, Thermodynamic irreversibilities and exergy balance in combustion processes, Progress in Energy and Combustion Science 34 (2008) 351376.

[28] R.J. da Silva, S.A. Nebra, Thermoeconomics analysis of cement production plants, in: ECOS'95, 1995, pp. 496501. 